\title{
A Study of Applications of RBF Network
}

\author{
Yojna Arora \\ Department of Computer \\ Science \& Engineering, ASET \\ Amity University, Haryana, \\ India
}

\author{
Abhishek Singhal \\ Department of Computer \\ Science \& Engineering, ASET \\ Amity University, Haryana, \\ India
}

\author{
Abhay Bansal \\ Department of Computer \\ Science \& Engineering, ASET \\ Amity University, Haryana, \\ India
}

\begin{abstract}
Forecasting is a method of making statements about certain event whose actual results have not been observed. It seems to be an easy process but is actually not. It requires a lot of analysis on current and past outcomes in order to give timely and accurate timely forecasted results.Radial Basis Function $(\mathrm{RBF})$ is a method proposed in machine learning for making predictions and forecasting. It has been used in various real time applications such as weather forecasting, load forecasting, forecasting about number of tourist and many such applications. The paper includes a detailed survey on RBF network on the basis of its evolution and applications. It also covers explanation about combination of RBF with other techniques such as Fuzzy, Neural Networkand Genetic Algorithm.
\end{abstract}

\section{Keywords}

RBF, Neural Network, RBF, Data Forecasting, Prediction

\section{INTRODUCTION}

Data Forecasting is something which is very important, let it be market analysis, weather, load of electricity for a city, expected calls in a call center etc., the whole idea revolves around having a prior estimate in order to make required preparations and get the best results. The prediction cannot be made in one go, rather it needs a detailed analysis of past data and based on the patterns extracted from the same, the future decisions are made. This is the main idea behind the training method termed as Supervised

Learning, in which a data set containing input and its corresponding mapped output, is fed as a reference and every time when a new input comes, it refers the already present data set and predicts the relevant output. A comparison of various supervised learning algorithms is explained in [1]. The main characteristic of Forecasting is that it is usually wrong, moreover, it needs to be timely and deal with real world applications in a better way. So, in order to make an accurate result, the adoption of good forecasting model is very important. Various Artificial neural network models for forecasting and decision making are presented in [2].

Thus, considering all these requirements RBF model is the one which is best suited. Although initially it was used only for the function of interpolation but now it's used for large scale prediction activities such as a Function Approximation [3], Time Series Prediction [4], Classification and System Control. The paper is further divided as Architecture description of RBF in Section II, Training of RBF network in Section III followed by detailed Literature Survey in section IV and Conclusion \& Future Scope in Section V.

\section{ARCHITECTURE}

The RBF network consists of three layers Input layer, Hidden layer and Output layer. It possess only a single hidden layer rather than multilayer structure, despite of this RBF can solve complex problems similar to a neural network with multiple intermediary layers. The reason behind the same is its capability to transform nonlinear input into linear output. The input field to each node of a hidden layer is nonlinear in nature and it is treated with radial activation function usually Gaussian Function. Further the final output is the weighted summation of these nonlinear inputs to the output layer, thus transforming non linearity into linearity.

Let the input data samples are denoted as:

$$
\mathrm{X}=\left[\begin{array}{lll}
\mathrm{x} 1 & \mathrm{x} 2 & \ldots \\
\mathrm{xn}
\end{array}\right]
$$

Then,

Output yi=fi $(x)=\sum_{i=1}^{N} w i \emptyset(|| X i-c i||)$

Where $i=1,2 \ldots \ldots n$ ( $n$ is the number of nodes at hidden layer)

$\mathrm{Wi}$ is the weight connecting the hidden layer to the output layer

$c i$ is the value of ith center in the hidden layer

$\|$.$\| is the Euclidean norm and finally,$

$\emptyset$ is the Radial Basis Function for which generally taken into consideration is Gaussian function

$$
\emptyset(\|\mathrm{x}-\mathrm{ci}\|)=\exp (-\|\mathrm{x}-\mathrm{ci}\| 2) / 2 \sigma 2
$$

The network design of RBF Network is shown in fig as:

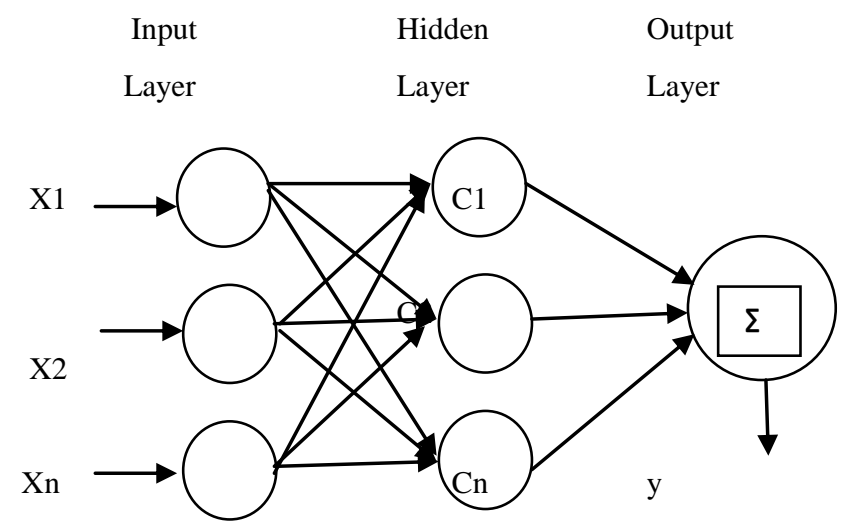

Figure 1.Network Structure of RBF model 
The most important factor that affects the success of RBF network is optimally choosing the parameters [5] i.e. no of nodes in the hidden layer. It is rather more important than even choosing an activation function. Since if choose less hidden layers nodes it will lead to a bad approximation to its contrary choosing large number will lead to the problem of over fitting.

\section{TRAINING OF NETWOK}

The factors that need to be determined for construction of an RBF network are:

- Choosing an appropriate value for the center

There are various methods which can be applied for the same, such as:

○ Randomly Selecting from the data set

- K means algorithm[6]

○ OLS Algorithm[7]

- Deciding the activation function to be implemented in hidden layer(Linear, Gaussian)

- Deciding the bias/spread value

- Adjusting the output weights (Gradient Descent, Least Square etc.) where

There is a need for normalization to be done as well. This can be done by using

$$
\overline{\mathrm{y}}=\frac{Y-Y \min }{Y \max -Y \min }
$$

Where $\mathrm{Y}$ is the actual value of the data sample

$\mathrm{Y}_{\max }$ takes the value larger than the foresting year

$\mathrm{Y}_{\text {min }}$ takes the value that is minimum from the sample of data

\section{LITERATURE REVIEW}

Taking RBF as a basic model and in combination with different techniques, it is used to solve various prediction problems.

Gradient Descent is applied to create a model for nonlinear, non-stationary time series predicted data as explained in [8].

The application of money exchanger also used RBF in combination with evolutionary algorithm [9].

Amount of air pollutant can be predicted when RBF is applied along with Principal Component Analysis (PCA) technique
[11]. Feed forward network helped in estimating the underground water level in [12].

The most advanced implementation of RBF includes its combination with Genetic Algorithm and Fuzzy Logic to predict load of electricity and wind respectively as explained in [13],[14].

A single stage RBF when extended to include multiple stages gives better results when forecasting exchange rates [15].

RBF has also been very helpful in predicting climatic conditions used in [16],[18].

RBF also helped in maintain security when it was used in detecting frauds and money laundering using APC-III and RLS technique [17].

A comparative study is done based on this which also depicts the improvement of RBF model from traditional to latest more accurate result oriented model as explained in Table below 


\begin{tabular}{|c|c|c|c|c|c|}
\hline Author's Name & Aim & $\begin{array}{l}\text { Technique } \\
\text { Applied }\end{array}$ & Key Features & Advantages & Application used \\
\hline E.S Chong[8] & $\begin{array}{l}\text { Model for nonlinear, Non } \\
\text { stationary Time Series } \\
\text { Prediction }\end{array}$ & Gradient Descent & Differentiated Data & $\begin{array}{l}\text { Can respond to } \\
\text { Gradient of Time } \\
\text { Series }\end{array}$ & Mac-Key Glass series \\
\hline V.M Rivas[9] & $\begin{array}{l}\text { To find number of } \\
\text { neurons in hidden layer, } \\
\text { center and } \\
\text { radii(Parameters) }\end{array}$ & $\begin{array}{l}\text { Evolutionary } \\
\text { Algorithm }\end{array}$ & $\begin{array}{l}\text { Binary Cross over } \\
\text { and Unary operator }\end{array}$ & $\begin{array}{l}\text { Optimize } \\
\text { Generalization error }\end{array}$ & Money Exchanger \\
\hline Read Zamora[10] & $\begin{array}{l}\text { Dynamic Data } \\
\text { Treatment to RRBF } \\
\text { network }\end{array}$ & RBF Network & Recurrent Neurons & $\begin{array}{l}\text { Learning Flexibility } \\
\text { of RBF network with } \\
\text { dynamic behavior of } \\
\text { recurrence neurons }\end{array}$ & $\begin{array}{l}\text { Mac-Key Glass } \\
\text { chaotic time series, } \\
\text { Logistic Map, } \\
\text { Prediction Non } \\
\text { Linear system }\end{array}$ \\
\hline $\begin{array}{l}\text { Wei-Zhen Lu, } \\
\text { Wen-Jian Wang, } \\
\text { Xie-Kang Wang, } \\
\text { Sui-Hang Yan, } \\
\text { Joseph C. } \\
\text { Lam[11] }\end{array}$ & $\begin{array}{l}\text { To propose a combined } \\
\text { PCA/RBF network }\end{array}$ & $\begin{array}{l}\text { Radial Basis } \\
\text { Function Network } \\
+ \text { Principal } \\
\text { Component } \\
\text { Analysis }\end{array}$ & $\begin{array}{l}\text { PCA optimizes the } \\
\text { parameters and RBF } \\
\text { introduces non } \\
\text { linearity }\end{array}$ & $\begin{array}{l}\text { Reliable } \\
\text { Cost effective } \\
\text { Simple Network } \\
\text { Architecture } \\
\text { Faster training Speed }\end{array}$ & $\begin{array}{l}\text { Air Pollutant } \\
\text { Forecasting }\end{array}$ \\
\hline $\begin{array}{l}\text { Ioannis N. } \\
\text { Daliakopoulosa, } \\
\text { Paulin } \\
\text { Coulibaly,Ioannis } \\
\text { K. Tsanisb[12] }\end{array}$ & $\begin{array}{l}\text { To find a network model } \\
\text { that can best suit in } \\
\text { predicting the results for } \\
\text { application }\end{array}$ & $\begin{array}{l}\text { Feed forward } \\
\text { network trained } \\
\text { with Levenberg- } \\
\text { Marquardt } \\
\text { algorithm }\end{array}$ & $\begin{array}{l}\text { Seven type of } \\
\text { network architecture } \\
\text { and training } \\
\text { algorithm compared }\end{array}$ & $\begin{array}{l}\text { Increased efficiency } \\
\text { and accuracy of } \\
\text { prediction }\end{array}$ & $\begin{array}{l}\text { Ground Water Level } \\
\text { forecasting }\end{array}$ \\
\hline $\begin{array}{l}\text { Yang Zhangang } \\
\text { Che Yanbo K.W. } \\
\text { Eric Cheng[13] }\end{array}$ & $\begin{array}{l}\text { To propose an improved } \\
\text { model for predicting the } \\
\text { electricity load of a city }\end{array}$ & $\begin{array}{l}\text { RBF Model with } \\
\text { Genetic Algorithm }\end{array}$ & $\begin{array}{l}\text { Genetic Algorithm } \\
\text { introduced for } \\
\text { optimizing the } \\
\text { parameters }\end{array}$ & $\begin{array}{l}\text { Forecasting Accuracy } \\
\text { and Convergence } \\
\text { speed improved }\end{array}$ & Load Forecasting \\
\hline $\begin{array}{l}\text { George Sideratos } \\
\text { Nikos } \\
\text { D.Hatziargyriou, } \\
\text { [14] }\end{array}$ & $\begin{array}{l}\text { To propose a model that } \\
\text { combines the techniques } \\
\text { of Neural Network and } \\
\text { Fuzzy Logic }\end{array}$ & $\begin{array}{l}\text { RBF model + } \\
\text { Fuzzy Model }\end{array}$ & $\begin{array}{l}\text { Quality indicator is } \\
\text { the fuzzy nodal and } \\
\text { RBF is used for the } \\
\text { final predication of } \\
\text { the results }\end{array}$ & $\begin{array}{l}\text { An improved model } \\
\text { with accurate results }\end{array}$ & Wind forecasting \\
\hline $\begin{array}{l}\text { Lean Yu } \\
\text { Kin Keung Lai, } \\
\text { Shouyang } \\
\text { Wang[15] }\end{array}$ & $\begin{array}{l}\text { To adopt an ensemble } \\
\text { model }\end{array}$ & $\begin{array}{l}\text { RBF model with } \\
\text { multiple stages }\end{array}$ & $\begin{array}{l}\text { The behavior of } \\
\text { model to use ruff at } \\
\text { multiple levels }\end{array}$ & $\begin{array}{l}\text { Problem of getting } \\
\text { trucked in local } \\
\text { minimum is resolved }\end{array}$ & $\begin{array}{l}\text { Exchange Rates } \\
\text { Forecasting }\end{array}$ \\
\hline $\begin{array}{l}\text { Dr. Taymoor A. } \\
\text { Awchi[16] }\end{array}$ & $\begin{array}{l}\text { To implement feed } \\
\text { forward and RBF } \\
\text { network on the } \\
\text { meteorological data set }\end{array}$ & RBF Network & $\begin{array}{l}\text { Climatic Conditions } \\
\text { (Temperature, } \\
\text { Rainfall, Sun shine } \\
\text { Hours etc) }\end{array}$ & $\begin{array}{l}\text { The better prediction } \\
\text { results by RBF as } \\
\text { compared to Feed } \\
\text { forward back } \\
\text { Propagation Model }\end{array}$ & Evapotransiration \\
\hline $\begin{array}{l}\text { Lin-Tao Lv, Na } \\
\text { Ji, Jiu-long } \\
\text { Zhang[117] }\end{array}$ & $\begin{array}{l}\text { To propose a new RBF } \\
\text { model with improved } \\
\text { predation performance }\end{array}$ & $\begin{array}{l}\text { RBF + APC- III } \\
\text { Algorithm +RLS } \\
\text { technique }\end{array}$ & $\begin{array}{l}\text { Bank Transaction } \\
\text { Details }\end{array}$ & $\begin{array}{l}\text { Enhanced fraud } \\
\text { detection rate and } \\
\text { reduced false positive } \\
\text { rate }\end{array}$ & $\begin{array}{l}\text { Anti-Money } \\
\text { Laundering }\end{array}$ \\
\hline
\end{tabular}




\begin{tabular}{|l|l|l|l|l|l|}
\hline $\begin{array}{l}\text { Tiruvenkadam } \\
\text { Santhanam and } \\
\text { A.C. } \\
\text { Subhajini[18] }\end{array}$ & $\begin{array}{l}\text { To predict the weather } \\
\text { conditions of a place } \\
\text { with an improvement in } \\
\text { basic model }\end{array}$ & $\begin{array}{l}\text { Non linear RBF } \\
\text { model with Linear } \\
\text { weight connection }\end{array}$ & $\begin{array}{l}\text { Linear Weights } \\
\text { introduced }\end{array}$ & $\begin{array}{l}\text { Improved results } \\
\text { (Faster Training } \\
\text { Time, Accuracy and } \\
\text { Reliability) }\end{array}$ & Weather Forecasting \\
\hline $\begin{array}{l}\text { HuaiQiang } \\
\text { Zhang[19] }\end{array}$ & $\begin{array}{l}\text { To compare back } \\
\text { propagation and RBF } \\
\text { network prediction }\end{array}$ & $\begin{array}{l}\text { Basic RBF } \\
\text { network }\end{array}$ & $\begin{array}{l}\text { Climate, } \\
\text { Government } \\
\text { policies, } \\
\text { Geography, Culture }\end{array}$ & $\begin{array}{l}\text { Good Prediction } \\
\text { Results }\end{array}$ & Tourist Prediction \\
\end{tabular}

\section{CONCLUSION}

RBF technique of Neural Network is used for making accurate predictions.Its application includes Money Laundering, Weather Forecasting, Wind Forecasting and many more where a prior knowledge about future is required.

In this paper, a general architecture of RBF i.e. its layered structure along with its mathematical formulations is proposed. A survey has also been done on various improvements of RBF Model i.e. from classical to most recent. During its development it is associated with different supporting techniques and for solving prediction related issues in many real time applications.

As far as future scope is concerned, two or more architecture proposed in the literature of this paper can be combined together to give more accurate results for the problems.

\section{REFERENCES}

[1] Rich Caruana and Alexandru Niculescu-Mizil, 2006, An Empirical Comparison of Supervised Learning Algorithms, Proceedings of the 23rd International Conference on Machine Learning, Pittsburgh, PA

[2] Leorrey Marquee, Marcus O' Connor and William Remus,1994,Artificial Neural Network Models for Forecasting and Decision Making, International Journal of Forecasting, Volume 10, Issue 1

[3] Guang-Bin Huang,P. Saratchandran, and Narasimhan Sundararajan,2005,A Generalized Growing and Pruning RBF(GGAP-RBF) Neural Network for Function Approximation, IEEE transactions on Neural Network, VOL. 16, No. 1

[4] Cheng-Ming Lee and Chia-Nan Ko,2009, Time series prediction using RBF neural networks with a nonlinear time-varying evolution PSOalgorithm,Journal Neurocomputing,Volume 73,

[5] Hui Peng, Tohru Ozaki, Valerie Haggan-Ozaki, and Yukihiro Toyoda,2003, A Parameter Optimization Method for Radial Basis Function Type Models, IEEE Transactionon Neyral Netwroks, VOL. 14

[6] J: K. Sing, D. K. Basu ,M. Nasipuri and M. Kundu, 2003, Improved K-means Algorithm in the Design of RBF Neural Networks, IEEE, VOL 2

[7] S Chen, C.F.N Cowen and P.M Grant, 1991, Orthogonal Least Squares Learning Algorithm For radial Basis Function Networks", IEEE transactions on Neural Network, VOL 2, No 2

[8] E. S. Chong, S. Chen, and B. Mulgrew,1996, Gradient Radial Basis Function Networks for Nonlinear and Nonstationary Time Series Prediction, IEEE Transactions on Neural Netwroks, VOL. 7, NO. 1

[9] V.M. Rivas,J.J. Merelo,P.A. Castillo,M.G. Arenas,J.G. Castellano,2003,Evolving RBF neural networks for timeseries forecasting with EvRBF, Elsevier

[10] Read Zamora, Daniel Racoceanu, amd Noureddine Zerhouni Laboratoire,2003, Recurrent radial basis function network for time-series prediction", Engineering Applications of Artificial Intelligence, Elsevier

[11] Wei-Zhen Lu,Wen-Jian Wang, Xie-Kang Wang, SuiHang Yan, and Joseph C. Lam,2004, Potential assessment of a neural network model with PCA/RBF approach for forecasting pollutant trends in Mong Kok urban air, Hong Kong”, Environmental Research

[12] Ioannis N. Daliakopoulos, Paulin Coulibaly and Ioannis K. Tsanis,2005, "Groundwater level forecasting using artificial neural networks", Journal of Hydrology"

[13] Yang Zhangang Che Yanbo K.W. Eric Cheng School,2007 Genetic Algorithm-Based RBF Neural Network Load Forecasting Model, IEEE

[14] George Sideratos and Nikos D. Hatziargyriou,2007,An Advanced Statistical Method for Wind Power Forecasting, IEEE Transactions on Power Systems, VOL. 22, NO. 1

[15] Lean Yu, Kin Keung Lai and Shouyang Wang,2008, Multistage RBF neural network ensemble learning for exchange rates forecasting", Neurocomputing

[16] Dr. Taymoor and A. Awchi, 2008, Application of Radial Basis Function Neural Networks for Reference Evapotranspiration Prediction", Al-Rafidain Engineering, Vol.16 No.1

[17] Lin-Tao Lv, Na Ji and Jhu- Long Zhang,2008, A RBF Neural Network Model For Anti-Money Laundering, Proceedings of the 2008 International Conference on Wavelet Analysis and Pattern Recognition, Hong Kong, 30-31

[18] Tiruvenkadam Santhanam and A.C. Subhajini,2011,An Efficient Weather Forecasting System using Radial Basis Function Neural Network", Journal of Computer Science

[19] HuaiQiang Zhang and JingBing Li ,2012, Prediction of Tourist Quantity Based on RBF Neural Network", Journal of Computers, VOL. 7, NO. 4. 